\title{
Charge Air Subcooling in a Diesel Engine via Refrigeration Unit - Effects on the Turbocharger Equilibrium
}

\author{
Diego Vittorini $^{\mathrm{a} *}$, Marco Di Bartolomeo ${ }^{\mathrm{a}}$, Davide Di Battista ${ }^{\mathrm{a}}$, Roberto Cipollone ${ }^{\mathrm{a}}$ \\ ${ }^{a}$ University of L'Aquila, Department of Industrial and Information Engineering and Economics, Via G. Gronchi 18, L'Aquila 67100, Italy
}

\begin{abstract}
The stringent regulations on fuel saving and emissions reduction in the transportation sector have become game-raisers in the development of present internal combustion engines for road applications, even if under-the-hood space constraints, downsizing and down-weighting prevent from adopting radical changes in the engine layout. Charge air cooling is the standard in present turbocharged diesel engines, to the point that a dedicated heat exchanger, fed by environmental air, is located downstream the compressor. The paper proves the option of an additional cooling through the cabin-heating unit - usually over-sized with respect to normal operation - very effective to increase charge air density and improve cylinder filling. The intercooler downstream the compressor would be provided with a lower thermal load, hence calling for smaller heat exchange surfaces, leading to reduced weight, space saving and no increased layout complexity. By pushing this idea forward, a properly sized cabin-heating unit could even supply enough air cooling to replace the intercooler instead of just assisting it, further raising the weight/space/layout advantages. In presence of an additional heat exchanger, the cooling efficiency would be no longer related to the vehicle speed and the benefit in terms of cylinder filling could be kept to the desired value on a wider operating range for the engine. Plus, the lower combustion temperatures associated with both a colder air and a more diluted charge approaching the chamber would also result in a more regular combustion process, in spite of a moderate penalty on the thermodynamic efficiency. The additional fuel consumption to compress the cooling fluid is always offset by the fuel saving with respect to normal operation and a beneficial effect is appreciated on emissions. Nonetheless, major variables to account for when evaluating the feasibility of such a layout are (i) the impact it has on the equilibrium of the turbocharger, i.e. on the efficiency at each operating point, (ii) to what extent the presence of a colder air affects the turbine/compressor matching and (iii) the rack position the ECU fixes at the VGT, to face both pressure losses at the additional evaporator and the different enthalpy content for both the air at the compressor outlet and the exhaust gases at the turbine inlet. A comprehensive experimental activity supported by a detailed 1D model of the engine unit, aimed at assessing the benefits of the air under-cooling, allowed to select the most appropriate cooling layout and, once validated based on the experimental evidence, to investigate the equilibrium at the turbocharger.
\end{abstract}

(C) 2018 The Authors. Published by Elsevier Ltd.

This is an open access article under the CC BY-NC-ND license (https://creativecommons.org/licenses/by-nc-nd/4.0/)

Selection and peer-review under responsibility of the scientific committee of the 73rd Conference of the Italian Thermal Machines Engineering Association (ATI 2018).

* Corresponding author. Tel.: +39-086-243-4319; fax: +39-086-243-4303.

E-mail address: diego.vittorini@ univaq.it 
Keywords: engine, intake air, efficiency, heat exchanger sizing, turbocharger equilibrium, 1D model

\section{Introduction}

In light of the always lower caps on both admissible fuel consumption and pollutants emissions for manufacturers to stay on the market, the vehicle efficiency is continuously addressed at both $R \& D$ and deployment level. The attempts to increase it mostly consist in either the integration of new on-board components in standard layouts or the development of innovative engine configurations, rather than a radical change in the engine set-up, with the additional complexity of meeting market requirements in terms of down-sizing and down-weighting. Either way, a more complex engine architecture comes out and results in a calibration method harder to implement, due to the higher amount of components and degrees of freedom to be tuned.

As a consequence, numerical modeling is becoming the standard in ICE development, as it allows a leaner development process, plus time and costs savings at once. This is particularly true for 1D codes, whose versatility makes them applicable in the concept phase as well as in the powertrain control and calibration stages. Moreover, the extensive literature available proves that the $1 \mathrm{D}$ modeling approach is a perfect fit for the investigation of a variety of operation-related aspects, with main areas of concern in the modeling of combustion [1,2], in-cylinder charge motion [3, 4], pollutants formation [5, 6], ducts dynamics [7, 8] and heat transfer [9, 10]. 1D models effectiveness is even higher when they integrate experimentally-supported empirical relations, hence preventing the lack in predictive capability, assuring results consistency with experimental evidence and providing a safe platform for engine control during operation (e.g. peak power at full load and minimum fuel consumption at part load). Moreover, the 1D codes accuracy is a key factor, since they often represent the early stages of a more detailed engine characterization, carried out on 3D simulation platforms for which they provide the numerical input $[11,12]$. In addition to the areas of application mentioned above, the 1D model approach is highly performing for the investigation of the engine performance enhancement through charge air cooling, an already consolidated technique in present turbocharged diesel engines, in which a dedicated heat exchanger allows to partly recover the issues associated with the air density reduction downstream the compressor (i.e. not proper cylinder filling and low volumetric efficiency) and to restore acceptable system efficiencies. Nonetheless, some operating and plant-layoutrelated issues - namely, the cooling capability/vehicle speed dependence, the radiator size in comparison to the under-the-hood space availability, weight increase and piping complexity - limit the advantages of such a layout and result in a $40-70^{\circ} \mathrm{C}$ intake air temperature at cylinders [13]. Previous studies by the Authors proved the feasibility of an additional air cooling through an evaporator at the intake manifold [13, 14]. Main strength of such a configuration has been proved to be in the fact that the conditioning unit already present on board for cabin heating/cooling purposes, oversized with respect to normal employment, can safely be in charge for the sub-cooling. Plus, the possibility to count on a dedicated evaporator for air cooling provides a better control of the engine performance over the whole operating regime for the engine, with no dependence on the relative speed between vehicle and outside air. Hence, no penalty would insist on the system, from either additional weight or unavailable room for the addition of a new component [13-16]. Both factors, indeed, along with system scalability, components packaging issues, low power density and the backpressure from an additional heat exchanger, limit the feasibility of the waste heat recovery through other techniques, such as exhaust-fed jet ejectors [17, 18], heat pumps [19], mechanically driven compression chillers [20], sorption-based cooling systems [21, 22, 23, 24], multi-stage air cooling [25] and cooling water-fed heat pumps [26, 27].

The idea of employing the cabin heating/cooling unit to provide charge air cooling represents a major breakthrough with respect to the research standard in the automotive sector $[13,14,28]$ and the novelty of such an application calls for an extensive modeling activity on the engine performances. 
The model, the Authors developed in-house on the 1D GT-Suite ${ }^{\mathrm{TM}}$ platform, moves from experimental data provided by an extensive experimental campaign on an turbocharged 3L IVECO F1C diesel engine, featuring an evaporator in the intake line. Based on the power, torque and EGR maps for normal operation, directly accessed from the ECU, the data allowed the proper model definition (e.g. heat exchange surfaces sizing, heat exchange and performance coefficient selection) over the whole NEDC cycle. Based on the experimental data, the best option in terms of heat exchanger type and layout turned out to be the one featuring a shell (R134a) and tube (air) heat exchanger in the intake manifold, as it maximizes the air sub-cooling at the cylinder intake. The 1D model confirms the effectiveness of such a layout and supports a proper heat exchanger sizing, dependently on engine type, suitability with the engine operation as defined by the NEDC homologation cycle and minimum power absorption by the compressor. Once validated based on the experimental evidence, the model allows to characterize the equilibrium of the turbocharging unit, in both presence and absence of the additional cooling, in terms of efficiency for both turbine and compressor and operating speed for the engine (i.e. for the turbocharger itself). The combined effect of increased pressure drops and modified thermodynamic coordinates for the group operation are investigated as well and the ECU-controlled adjustment on the VGT is assessed, by monitoring the rack position in every operating point of interest.

\section{Preliminary experimental activity}

Ten engine operating steady points were performed for a $120 \mathrm{~s}$ duration, varying the engine speed from 1200 to $3600 \mathrm{rpm}$, repeated at 100 and $200 \mathrm{Nm}$. The IVECO F1C diesel engine air cooling system, already featuring a tap water-fed intercooler, is integrated through a R134a single pass counter-flow shell and tube heat exchanger, responsible for the air undercooling downstream the intercooler (Figure 1). Such a layout is selected among all those possible as the most effective one, i.e. the one assuring a proper utilization for the intercooler, the lowest air temperature at the manifold intake and the lowest pressure drops in the intake runner [13]. The uncertainty affecting the measures is in Table 1. A temperature reduction in the $15-30 \mathrm{~K}$ range is appreciated with the air cooling unit on (A/C ON), with little differences between the $100 \mathrm{Nm}$ and $200 \mathrm{Nm}$ torque, corresponding to a heat removal at the evaporator in the 0.3-2.5 kW, depending on the air mass flow rate (Figure 2). Generally speaking, the lower the air mass flowing in the runner and eventually in the heat exchanger (i.e. the lower the engine load), the lower the heat exchange and hence, the lower the gain with respect to normal operation with no air cooling (A/C OFF). The mechanical power absorption by the compressor ranges between $212 \mathrm{~W}$ and $520 \mathrm{~W}$, when the air mass flowrate shifts from $100 \mathrm{~kg} / \mathrm{h}$ to $480 \mathrm{~kg} / \mathrm{h}$ and increases with the air mass flow rate being processed, in accordance with expectations.

Table 1. Measurements uncertainty

\begin{tabular}{cccc}
\hline Temperature $\left[{ }^{\circ} \mathrm{C}\right]$ & \pm 2.2 & Air mass flowrate $[-]$ & $\pm 3 \%$ \\
Pressure [mbar] & \pm 0.8 & Fuel mass flowrate $[-]$ & $\pm 1 \%$ \\
\hline
\end{tabular}

The benefit achieved on the air mass flowrate entering the cylinder is in Figure 3, along with the increase in the engine global efficiency: a 5.7\% increase in the air mass approaching the cylinder is appreciated at $1800 \mathrm{rpm}$, followed by $3.9 \%$ increase at $3000 \mathrm{rpm}$. A slightly different trend is appreciated on the engine global efficiency, for which a higher spread occurs as the engine speed varies: the efficiency increase tops $4.6 \%$ at $1200 \mathrm{rpm}$, with the lowest at $2400 \mathrm{rpm}(1.5 \%)$. The in between values range between $2 \%$ and $3 \%$, with negligible differences among engine speed values. Pressure drops monitored on the air side are not negligible, though, and reach 100 mbar at 450 $\mathrm{kg} / \mathrm{h}, 200 \mathrm{Nm}$ engine load (Figure 4): dependently on the operating regime, such a penalty offsets the pressure boost achieved through the ECU-controlled variable geometry turbine and reflects on the manifold intake pressure, where a $20 \mathrm{hPa}$ maximum penalty occurs. 


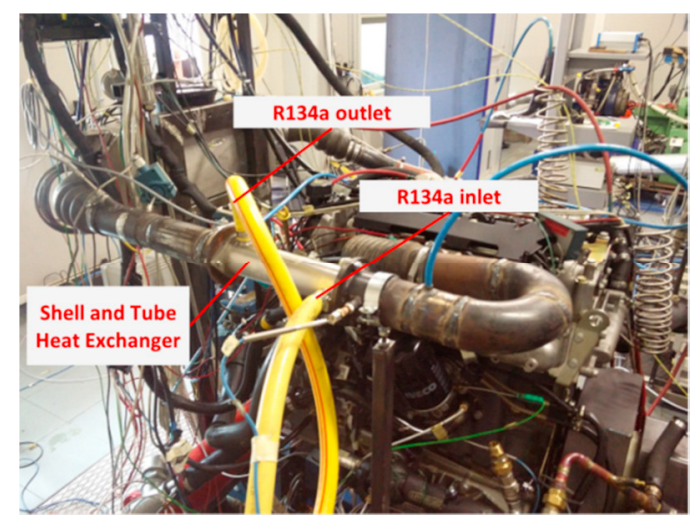

Figure 1. Downstream undercooling layout

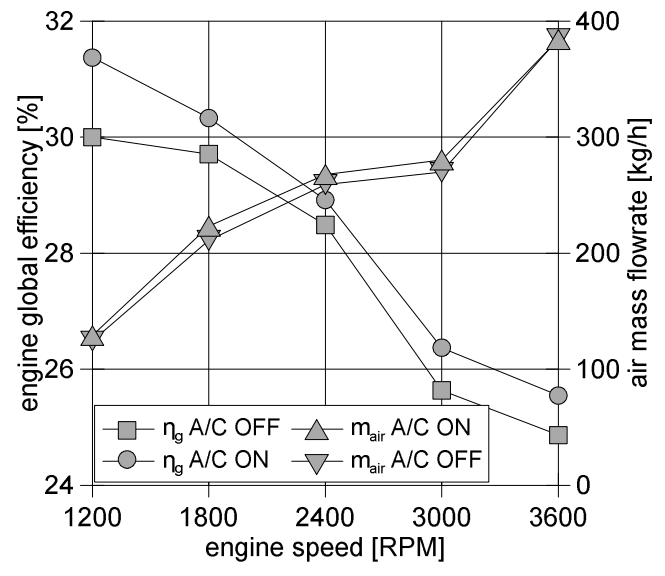

Figure 3. Air mass flow rate and engine global efficiency

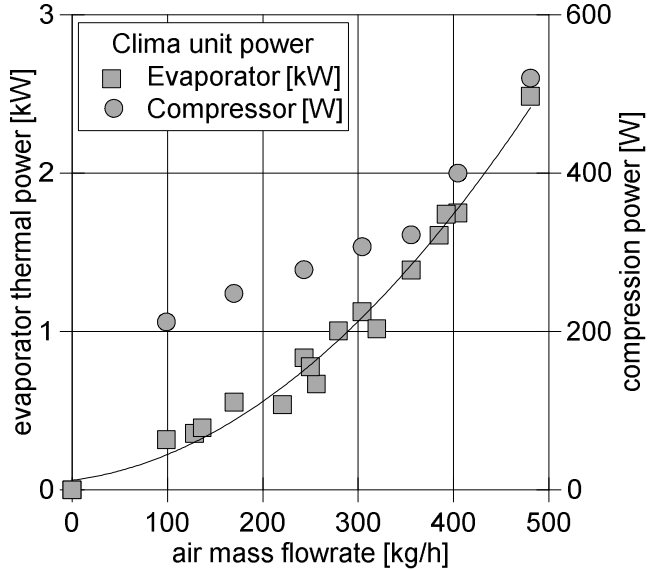

Figure 2. Clima unit power

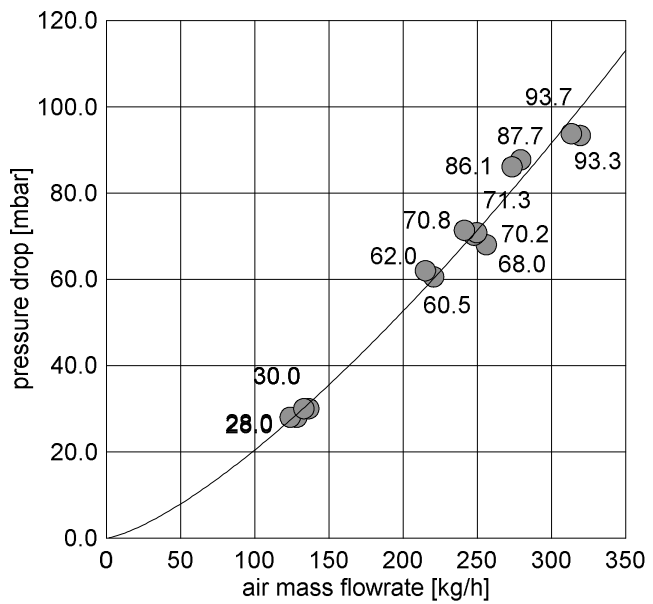

Figure 4. Subcooling unit air side pressure drops

\section{Model validation and equilibrium assessment for the turbocharger}

Specifics for all engine subsystems the GT Suite ${ }^{\mathrm{TM}}$ model accounts for are in Table 2. Look-up tables and PID controllers allow to reproduce the ECU control over the engine at a model level, with main control variables in the boost pressure and the amount of fuel being injected - as a function of engine speed and engine load - and the rack position via ECU actuation [29]. Intake and exhaust manifolds were modeled as elementary ducts - rectilinear or curvilinear - along with fittings and connecting elements. Geometry and operation-related coefficients (e.g. friction, discharge, heat exchange) were specified at the model initialization [30]. Filling/emptying processes have been included, accounting for the mass trapping inside the cylinder. Same goes for the combustion process, the gas/wall heat transfer and the work availability at the shaft. Conservation equations for mass, momentum and energy are solved for steady states, according to specified boundary conditions. For instance, the target intake pressure is fixed by the ECU actuation on the VGT.

A three-Wiebe model describes the burned fuel fraction as a function of the crankshaft angle and the combustion phase (i.e. premixed, diffusive, oxidation-controlled): the injection timing and the diffusive combustion duration are assigned [16] and the power at the shaft calculated accordingly, under the condition that the cumulative burned fuel fraction adds up to 1 . Woschni correlation regulates the heat transfer in the cylinder. Real maps for both turbine and compressor of the turbocharging system are introduced as well. 
Table 2. IVECO F1C 3.0L data and model parameters

\begin{tabular}{cclc}
\hline Bore [mm] & 95.8 & Peak power [kW] & 130 \\
Stroke [mm] & 104 & Peak torque [Nm] & 402 \\
Connecting rod length [mm] & 220 & Ignition sequence & $1-3-4-2$ \\
Displacement per cylinder [L] & 0.75 & IVC [CSA] & -160 \\
Total displacement [L] & 2.998 & EVO [CSA] & 183 \\
Cylinders number & 4 & IVO [CSA] & 340 \\
Compression ratio & $19: 1$ & EVC [CSA] & 366 \\
\hline
\end{tabular}

Experimental data referring to $100 \mathrm{Nm}$ engine load allow the model validation (Figure 5): when the boost pressure is assumed as the control variable, a maximum $8 \%$ difference is appreciated, with the engine speed varying between $1200 \mathrm{rpm}$ and $3600 \mathrm{rpm}$. The model underestimates the torque, with a $10 \%$ maximum error, occurring at $2400 \mathrm{rpm}$, which confirms about the good fit between experimental and simulated data, especially considered the relevance of the torque datum in the engine characterization. This assures about the fact that a negligible shift has to be expected between predicted and experimental data and that the only source of bias are (i) the extrapolation procedure performed on the characteristic curves for the turbine - to properly account for the choke on the air mass flowrate admitted to the rotor stage - and (ii) the shell and tube heat exchanger modeling, particularly sensitive in 1D models to the correlation adopted to describe thermal interactions both within the heat exchanger (e.g. flow splitting, air/refrigerant heat exchange coefficients) and with the surroundings (e.g. wall heat transfer coefficients). As far as the heat exchanger modeling is concerned, a Colburn-Klimenko relation for heat transfer seems to be particularly suitable for a detailed description of refrigerants evaporation at the temperature and pressure levels at hand [28, 31].

As far as the extrapolation on the manufacturer data for the Garrett Turbocharger T202H(50)T74 VGT Turbine Compressor C224(60)T50 is concerned, [32] provides the best option for data correction, in presence of a variable geometry admission section to the rotor stage. The equilibrium point for every mass flow rate of interest remains completely defined (i.e. rpm, compression and expansion ratio), once the ECU provides the boost pressure at given engine speed and load, as in Figure 6-7. Iso-lines for efficiency and rack opening are reported for the turbine, to allow a complete characterization of the operating condition for the unit. Same goes for the compressor, with the efficiency and the revolution speed as parameters. For sake of clarity, Figure 6-7 only report experimental data for the $100 \mathrm{Nm}$ engine load and suggests that the group equilibrium is not strongly affected by the additional cooling performed on the air. Each point on the charts corresponds to an assigned engine speed and engine torque: they are close each other and little variations are appreciated on the reduced mass flowrate, independently on the regime of additional cooling that applies. Same goes for the turbine and compressor efficiency. The temperature experiences a 15-30 K reduction at the intake manifold, dependently on the engine speed, and such a variation is mirrored by the one at the turbine inlet. As the engine speed increases, the rack always closes up a bit, to compensate pressure losses at the evaporator and results in a group equilibrium almost unaffected by the changes in the thermodynamic coordinates of the turbocharging unit:

- $\quad$ point A (1200 rpm engine, $40000 \mathrm{rpm}$ turbo): the low engine speed leads to a low mass flowrate and the increase in air density from the additional cooling does not affect the group equilibrium, with a 50\% compressor efficiency and a 39\% turbine efficiency. 27.8 mbar pressure losses occur at the evaporator;

- point B (1800 rpm engine, $70000 \mathrm{rpm}$ turbo): a negligible (2\%) reduction on the speed of the group is appreciated. Both the compressor and the turbine efficiency are slightly higher with the subcooling (1.5\% and $2 \%$, respectively). No additional pressure losses occur at the under-cooling section (56.5 mbar) and consequently, the rack position stays the same;

- point C (2400 rpm engine, $75000 \mathrm{rpm}$ turbo): the greatest shift is on the turbine section, with a $3.2 \%$ efficiency reduction, entirely due to the lower enthalpy content (i.e. the lower temperature) of the exhaust gases at the turbine inlet, due to the more diluted charge in the cylinders. The compressor efficiency tops $70 \%$ in both cases. These data suggest that the ECU controlled VGT-rack opens a bit and effectively compensates the increasing pressure losses (71.8 mbar) at the evaporator; 
- point D (3000 rpm engine, 85000 turbo): the group is unaffected by the additional cooling, as both the turbine and the compressor keep working at fixed point. Compressor and turbine efficiency tops $72 \%$ and $64 \%$, respectively, with a pressure drop that never exceeds 87.8 mbar;

- point E (3600 rpm engine, $95000 \mathrm{rpm}$ turbo): a $4.2 \%$ efficiency increase is appreciated on the turbine (55\% efficiency with no additional cooling), whilst the compressor efficiency stays constant (74.3\%). Such a behavior results from a more effective actuation by the ECU on the rack, whose opening provides the fluid with smoother access conditions to the rotor. The VGT is here confronted with the most severe pressure disturbance by the evaporator: the pressure drop, indeed, tops $147.7 \mathrm{mbar}$ here, i.e. the maximum value among all those experimentally assessed.

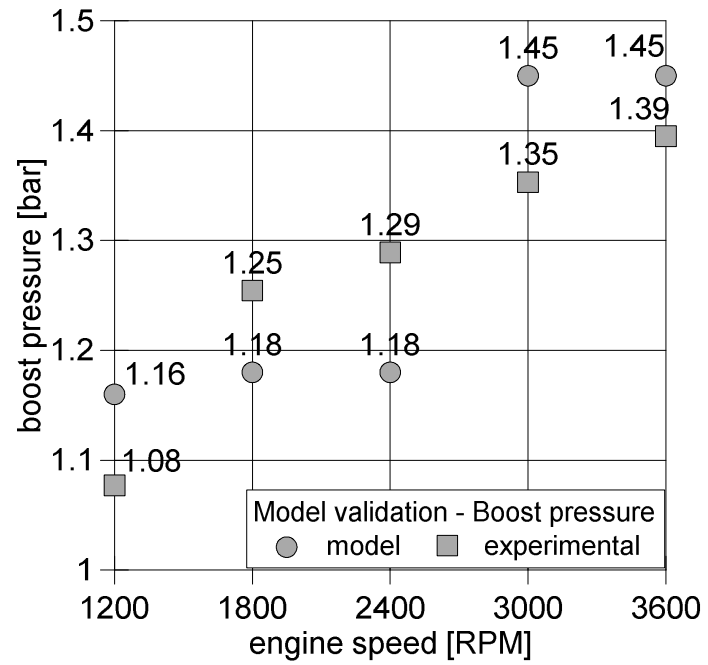

(a)

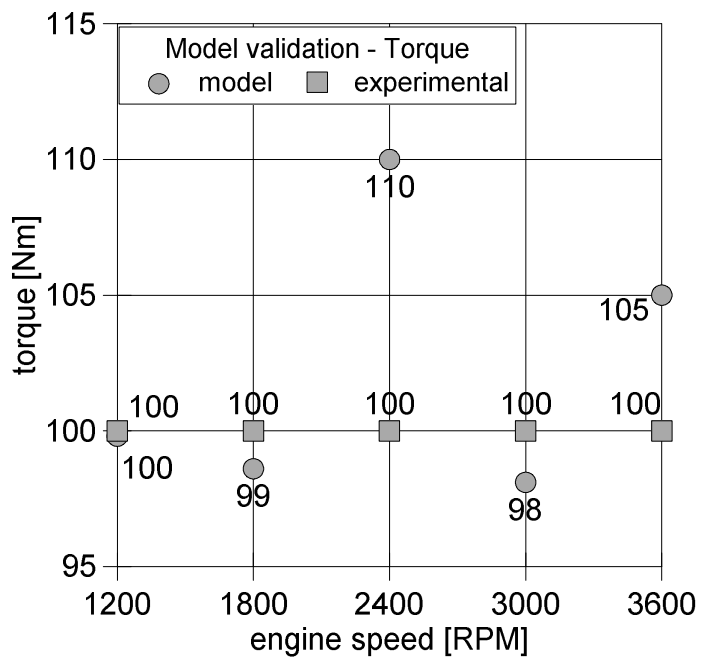

(b)

Figure 5. Predicted vs experimental data - Boost pressure (a), torque (b)

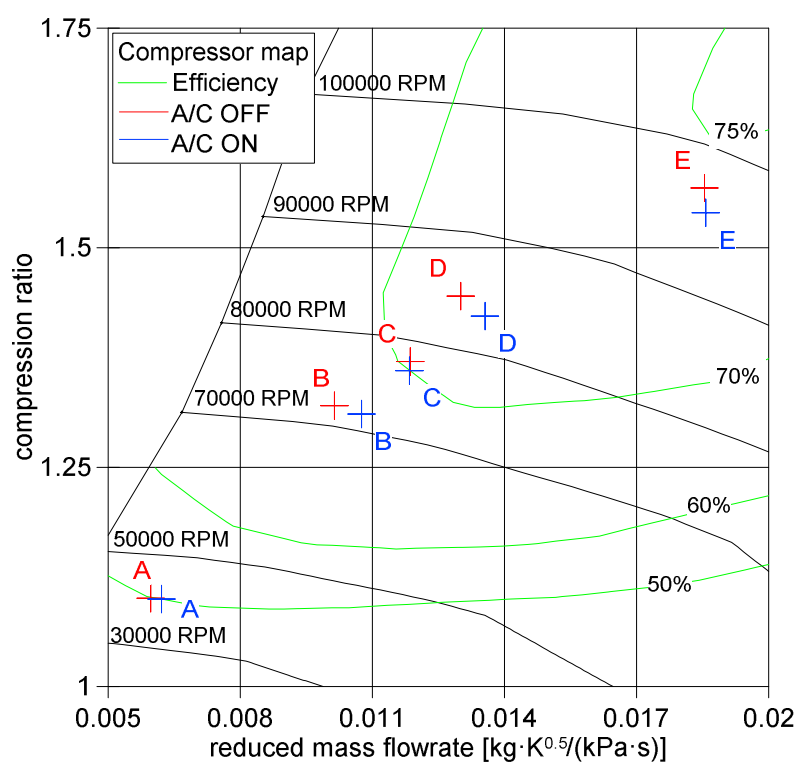

Figure 6.Compressor map

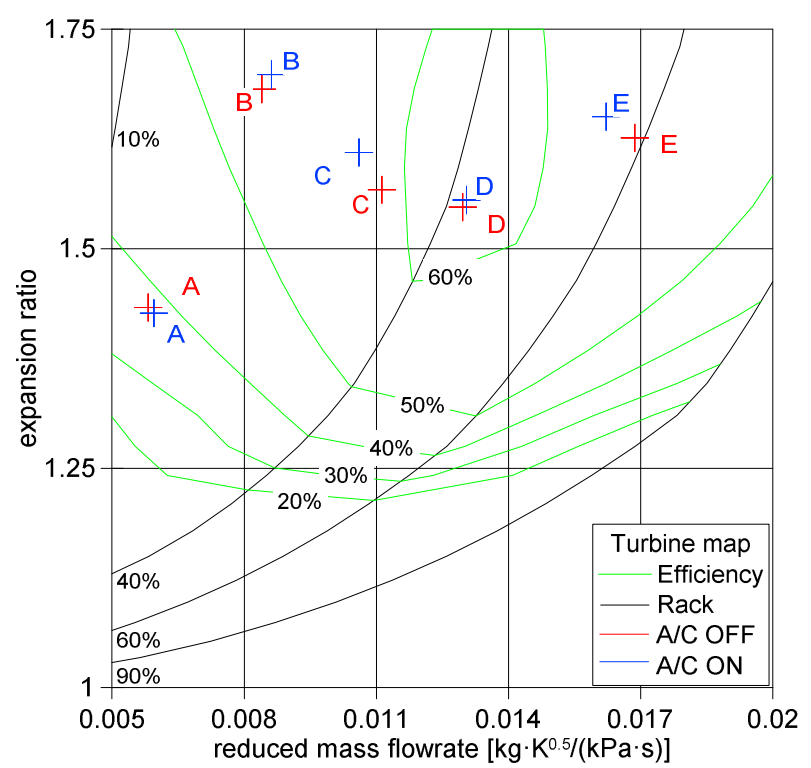

Figure 7. Turbine map 


\section{Conclusions}

A comprehensive analysis of a turbocharged diesel engine for heavy duty applications was performed, through both an extensive experimental characterization and a detailed virtual modeling activity, to assess the effectiveness of an additional charge air cooling. A sheet and tube evaporator was integrated to the existing layout and placed downstream the compressor, at the intake manifold and fed with R134a, with the intention to reproduce operating conditions and cooling capabilities of a standard cabin heating unit. The potential of such a unit to replace the already on-board intercooler is also evaluated, due to its reflections on the size/weight benefits it assures. A heat removal in the range $0.3-2.5 \mathrm{~kW}$ is possible, dependently on the operating conditions (engine speed and engine load) for the system at hand, with an average $15-30 \mathrm{~K}$ temperature reduction at both the intake manifold and turbine inlet, i.e. a lower temperature combustion within the cylinder. Along with the obvious benefits such an engine set-up has, in terms of down-sizing, down-weighting, fuel consumption and emissions reduction, the presence of an additional air cooling unit leads to modified thermodynamic coordinates for the turbocharging group, as the compressor faces higher pressure losses and the turbine is fed with a lower enthalpy content, due to the more diluted charge within the cylinder. Based on experimental data and the findings of a validated 1D model of both components and connections in the engine set-up at hand, various operating conditions were swept and the equilibrium of the turbocharging unit was assessed. The turbocharger does not suffer the presence of the additional heat exchanger: for a $100 \mathrm{Nm}$ engine load, the turbocharger speed experiences $2 \%$ maximum variations, dependently on the operating points being considered; even smaller variations occur on the rack position. The efficiency value for both turbine and compressor stays the same with and without the air subcooling unit and the effect of the pressure losses is negligible, mostly due to the VGT compensation of both the increased resistance to the fluid motion within the pipes and the modification of the thermodynamic state for the air being compressed and the exhausts approaching the turbine.

\section{References}

[1] Teodosio, L., Attilio, R., Nonatelli, F., "A 1D/3D Methodology for the Prediction and Calibration of a High Performance Motorcycle SI Engine", Energy Procedia 82 (2015): 936-943, https://doi.org/10.1016/j.egypro.2015.11.842

[2] De Bellis, V., Bozza, F., Siano, D., Gimelli, A., "Fuel Consumption Optimization and Noise Reduction in a Spark-Ignition Turbocharged VVA", SAE Int. J. Engines 6(2):2013, doi:10.4271/2013-01-1625

[3] De Bellis, V., Severi, E., Fontanesi, S., Bozza, F., "Hierarchical 1D/3D Approach for the Development of a Turbulent Combustion Model Applied to a VVA Turbocharged Engine". Part I: Turbulence Model, Energy Procedia, Volume 45, 2014, Pages 829-838, ISSN 1876-6102 http://dx.doi.org/10.1016/j.egypro.2014.01.088

[4] Grasreiner, S., Neumann, J., Luttermann, C., Wensing, M., Hasse, C., "A Quasi-Dimensional Model of Turbulence and Global Charge Motion for Spark Ignition Engines with Fully Variable Valvetrains”, International Journal of engine Research 15(7) 805-816, IMechE 2014, DOI: $10.1177 / 1468087414521615$

[5] Richard, S., Bougrine, S., Font, G., Lafossas, F.A., Le Berr, F., "On the Reduction of a 3D CFD Combustion Model to Build a Physical 0D Model for Simulating Heat Release, Knock and Pollutants in SI Engines", Oil \& Gas Science and Technology - Rev. IFP, Vol. 64 (2009), No. 3, pp. 223-242. doi: 10.2516/ogst/2008055

[6] Ma, G., Tauzia, X., Maiboom, A., "One-dimensional combustion model with detailed chemistry for transient diesel sprays", Proceedings of the Institution of Mechanical Engineers, Part D: Journal of Automobile Engineering 228(4), pp. 457-476, IMechE 2014, https://doi.org/10.1177/0954407013518036

[7] Lee, T.K., Filipi, Z.S., "Improving the Predictiveness of a Quasi-D Combustion Model for Spark Ignition Engines with Flexible Intake Systems", International Journal of Automotive Technology, 2011, Vol. 12, No. 1, pp. 1-9

[8] Montenegro, G., Onorati, A., Cerri, T., Della Torre, A., "A Quasi-3D Model for the Simulation of the Unsteady Flows in I.C. Engine Pipe Systems", SAE Technical Papers (2012), DOI: 10.4271/2012-01-0675

[9] Cipollone, R., Di Battista, D., Gualtieri, A., "A novel engine cooling system with two circuits operating at different temperatures", Energy Conversion and Management 75 (2013), pp. 581-592, DOI: 10.1016/j.enconman.2013.07.010

[10] Sideri, M., Berton, A., D'Orrico, F., "Assessment of the wall heat transfer in 3D-CFD in-cylinder simulations of high performance diesel engines", Energy Procedia 126, 2017, pp.963-970, https://doi.org/10.1016/j.egypro.2017.08.187

[11] Dimitriou, P., Avola, C., Burke, R., Copeland, C., Turner, N., "A Comparison of 1D-3D Co-Simulation and Transient 3D Simulation for EGR Distribution Studies”, ASME 2016 Internal Combustion Engine Division Fall Technical Conference, Paper No. ICEF2016-9361, pp. V001T06A010; 11 pages, doi:10.1115/ICEF2016-9361

[12] Liang, L., Ge, H., Ge, H., and Zhao, P., "A 1-D Platform to Simulate the Effects of Dedicated EGR on SI Engine Combustion," SAE Technical Paper 2017-01-0524, 2017, https://doi.org/10.4271/2017-01-0524

[13] Cipollone, R., Vittorini, D., Di Battista, D., Di Bartolomeo, M., "Optimization of the Engine Intake Air Temperature through the Air Conditioning Unit”, SAE Technical Paper 2018-01-0973, 2018, doi:10.4271/2018-01-0973 
[14] Cipollone, R., Vittorini, D., Di Battista, D., "Experimental Assessment of Engine Charge Air Cooling by a Refrigeration Unit," Energy Procedia 126:1067-1074, ISSN 1876-6102, 2017, doi:10.1016/j.egypro.2017.08.226.

[15] Harada, M., Yasuda, T., Terachi, S., Pujols, S. et al., "Water Cooled Charge Air Cooler Development," SAE Technical Paper 2016-01-0651, 2016, doi:10.4271/2016-01-0651

[16] Cipollone, R., Di Battista, D., Gualtieri, A., and Massimi, M., "Development of Thermal Modeling in Support of Engine Cooling Design," SAE Technical Paper 2013-24-0090, 2013, doi:10.4271/2013-24-0090.

[17] Zegenhagen, M.T., and Ziegler, F. (2015) "Feasibility analysis of an exhaust gas waste heat driven jet-ejector cooling system for charge air cooling of turbocharged gasoline engines" Applied Energy 160 (2015): 221-230

[18] Zegenhagen, M.T., and Ziegler, F. (2015) "Experimental investigation of the characteristics of a jet-ejector and a jet-ejector cooling system operating with R134a as a refrigerant" Int. J. Refrig. 56 (2015): 173-185

[19]Gentner, H. (1995) "Vergleichende Untersuchung von mechanics, elektrisch un thermisch angetriebenen Kälteanlagen für Fahrzeugklimatisierung" VDI-Forschungsberichte Reihe 19.82 (1995)

[20] Guhr, C. (2011) "Verbesserung von Effizienz und Dynamk eines hubraumkleinen turboaufgeladenen 3-Zylinder-DI-Ottomotors durch Abgasrückführung und ein neues Ladeluftkühlkonzept" PhD Thesis TU Dresden

[21] Manzela, A.A., Hanriot, S.M., Gomez, L.C., and Sodre, J.R. (2010) "Using engine exhaust gas as energy source for an absorption refrigeration system" Appl Energy 8 (2010): 1141-1148

[22] Novella, R., Dolz, V., Martìn, J., and Royo-Pascual, L. (2017) "Thermodynamic analysis of an absorption refrigeration system used to cool down the intake air in an internal combustion engine" Appl. Therm Eng 111 (2017): 257-270

[23] Liu, J., and Xu, S. (2013) "The performance of absorption-compression hybrid refrigeration driven by waste heat and power from coach engine" Appl. Therm. Eng. 61.2 (2013): 747-757

[24] Rêgo, A.T., Hanriot, S.M., Oliveira, A.F., Brito, P., and Rêgo, T.F.U. (2014) "Automotive exhaust gas flow control for an ammonia-water absorption refrigeration system" Appl. Therm. Eng. 64.1-2 (2014): 101-107

[25] Tamainot-Telto, Z., Metcalf, S.J., and Critoph, R.E., (2009) "Novel compact sorption generators for car air conditioning" Int J Refrig 32 (2009): 236-241

[26] Zhang, L.Z. (2000) "Design and testing of an automobile waste heat adsorption cooling system" Appl. Therm Eng 20 (2000): 103-114

[27] D. Di Battista, M. Mauriello, R. Cipollone, Waste heat recovery of an ORC-based power unit in a turbocharged diesel engine propelling a light duty vehicle, Applied Energy, Volume 152, 15 August 2015, Pages 109-120, ISSN 0306-2619, https://doi.org/10.1016/j.apenergy.2015.04.088.

[28] Di Battista, D., Cipollone, R., "High efficiency air conditioning model based analysis for the automotive sector", International Journal of Refrigeration, Volume 64, April 2016, Pages 108-122, ISSN 0140-7007, https://doi.org/10.1016/j.jirefrig.2015.12.014.

[29] Di Battista, D., Cipollone, R. "Experimental and numerical assessment of methods to reduce warm up time of engine lubricant oil", (2016) Applied Energy, 162, pp. 570-580

[30] Cipollone, R., Di Battista, D., Gualtieri, A. "Energy recovery from the turbocharging system of internal combustion engines", (2012) ASME $201211^{\text {th }}$ Biennial Conference on Engineering Systems Design and Analysis, ESDA 2012, 2, pp. 477-487

[31] Di Battista, D., Di Bartolomeo, M., Villante, C., Cipollone, R. A Model Approach to the Sizing of an ORC Unit for WHR in Transportation Sector, (2017) SAE International Journal of Commercial Vehicles, 10 (2),

[32] Villante, C., Valente, R., "A Study on High Rate EGR in a Medium Size Turbo-Charged CI ICE Both in Low and High Pressure Configurations”, SAE 2009-24-0078 Technical Paper 